\title{
Trending ability and limitations of transpulmonary thermodilution and pulse contour cardiac output measurement in cats as a model for pediatric patients
}

\author{
Annette P. N. Kutter • Rima N. Bektas • \\ Christoph K. Hofer • M. Paula Larenza Menzies • \\ Regula Bettschart-Wolfensberger
}

Received: 4 February 2014/ Accepted: 11 September 2014/Published online: 17 September 2014

(C) Springer Science+Business Media New York 2014

\begin{abstract}
The present study evaluated transpulmonary thermodilution (TPTD) and pulse contour cardiac output (PCCO) both measured by the PiCCO Plus ${ }^{\mathrm{TM}}$ monitor (Pulsion Medical Systems, Munich, Germany) against pulmonary artery thermodilution (PATD) in cats as a hemodynamic model for small children. A wide range of cardiac outputs (CO) was simultaneously measured. Accuracy and trending abilities were critically evaluated. Three cats were studied under isoflurane anesthesia and $160 \mathrm{CO}$ measurements were performed with $3 \mathrm{~mL}$ ice-cold $5 \%$ dextrose with PATD and TPTD. The results were compared with the PCCO measurement before the bolus measurement. Cardiac output was manipulated from 32 to $224 \mathrm{~mL} / \mathrm{kg} / \mathrm{min}$ by dobutamine, dopamine, phenylephrine, medetomidine and increased concentrations of isoflurane. Bland-Altman analysis, concordance and polar plot analysis were performed to assess accuracy and trending ability. TPTD was measuring constantly higher than PATD with a mean bias of $73 \mathrm{~mL} / \mathrm{kg} / \mathrm{min}$ and limits of agreement of $34-112 \mathrm{~mL} / \mathrm{kg} / \mathrm{min}$, a concordance rate of $94 \%$ and a mean polar angle of $-5^{\circ}$ with radial limits of agreement (RLOA) of $33^{\circ}$. Concordance rate of the PCCO versus PATD was $82 \%$ with a mean polar angle of $-10^{\circ}$ and RLOA of $46^{\circ}$ and versus TPTD $90 \%$ with a mean polar
\end{abstract}

\footnotetext{
A. P. N. Kutter $(\bowtie) \cdot$ R. N. Bektas · M. P. Larenza Menzies · R. Bettschart-Wolfensberger

Section of Anesthesiology, Equine Department, Vetsuisse

Faculty, University of Zurich, Winterthurerstr. 260, 8057 Zurich, Switzerland

e-mail: akutter@vetclinics.uzh.ch

C. K. Hofer

Institute of Anesthesiology and Intensive Care Medicine, Triemli City Hospital, Birmensdorferstrasse 497, 8063 Zurich,

Switzerland
}

angle of $-6^{\circ}$ and RLOA of $46^{\circ}$. Both tested methods constantly overestimated simultaneous PATD measurements. The small size, low flows and the relative short catheter not reaching the abdominal aorta may explain that. However TPTD tracked changes accurately opposed to a poor trending ability of the PCCO measurement.

Keywords Monitoring · Hemodynamic $\cdot$ Cardiac output · Thermodilution $\cdot$ Pediatrics

\section{Introduction}

Low cardiac output (CO) can tremendously increase mortality in pediatric patients [1] and children in septic shock are prone to develop cardiogenic shock compared to adults [2]. In critically ill small children hemodynamic monitoring relies upon pressure-based and metabolic parameters $[3,4]$ even if hemodynamic support directed to $\mathrm{CO}$ goals is recommended [5]. Estimation of $\mathrm{CO}$ by means of clinical parameters is not adequate in children $[6,7]$.

The placement of a pulmonary artery catheter (PAC) to measure $\mathrm{CO}$ is avoided in children under $10 \mathrm{~kg}$ since this carries risks of thrombosis, arrhythmias and perforation [8]. Transpulmonary thermodilution (TPTD) compared favorably in patients or animals with a bodyweight of $<10 \mathrm{~kg}$ [913] and is considered to be the clinical standard for bolus $\mathrm{CO}$ measurements in the pediatric critical care setting [14].

However, there is lack of a validated continuous CO measurement in the pediatric population and an accurate, safe and reliable measure thereof needs to be defined [3, 15]. The continuous pulse contour $\mathrm{CO}$ measurement by the PiCCO Plus ${ }^{\mathrm{TM}}$ (Pulsion Medical Systems, Munich, Germany) monitor [pulse contour cardiac output (PCCO)] that is calibrated via TPTD is considered to be an important 
advanced monitoring system in critically ill children [16] despite the fact that the accuracy and trending ability of the continuous mode have been questioned [17, 18].

The aim of the current study was to assess the accuracy and the trending ability of the intermittent TPTD and the continuous PCCO. The limitations of these PiCCO Plus ${ }^{\mathrm{TM}}$ techniques and the reference technique, i.e. the pulmonary artery thermodilution (PATD) in small animals and under low flow conditions are discussed as a model for critically ill children.

\section{Materials and methods}

\subsection{General}

The study was approved by the federal ethical committee on animal research of the Canton Zurich, Switzerland. Three male adult cats weighing 4.2, 4.5 and $5.6 \mathrm{~kg}$ were investigated under general anesthesia. After inhalational induction using isoflurane, their trachea was intubated using a $4.5 \mathrm{~mm}$ internal diameter (I.D.) cuffed endotracheal tube (Air-Cuf ${ }^{\circledR}$, Bivona Inc., Gary, Indiana, USA) and their lungs were mechanically ventilated using volume-controlled ventilation (Megamed $700^{\circledR}$, Megamed, Cham, Switzerland) targeting an end-tidal $\mathrm{CO}_{2}$ of $35 \pm 5$ torr $(4.7 \pm 0.7 \mathrm{kPa})$. Anesthesia was maintained with isoflurane to effect in $40 \%$ oxygen. A constant rate infusion of fentanyl was given with a rate of $5 \mathrm{mcg} / \mathrm{kg} / \mathrm{h}$.

\subsection{Instrumentation}

After induction of anesthesia a 5-Fr introducer sheath (Arrow International, Reading, USA) was placed in an external jugular vein and a 3-Fr $(7 \mathrm{~cm})$ thermistor tipped femoral artery catheter (Pulsiocath PV2013L07, Pulsion Medical Systems, Munich, Germany) was introduced into a femoral artery, both by means of a surgical cut-down. A 4-Fr Swan-Ganz catheter (Arrow International, Reading, USA) was inserted through the jugular placed introducer sheet and guided under fluoroscopic control. Both ports of the Swan-Ganz catheter and the femoral arterial line were connected to pressure transducers all with low-compliance saline filled tubing. All transducers were zeroed and positioned at the level of the right atrium. To avoid damping and air bubbles in the fluid filled system and to ensure an optimal curve analysis all arterial pressure lines were flushed continuously with $4 \mathrm{~mL} / \mathrm{h}$ of $0.9 \%$ saline.

\subsection{Cardiac output measurements}

A fluid bolus of $3 \mathrm{~mL}$ ice-cold $5 \%$ dextrose was manually injected by the same operator into the proximal port of the pulmonary artery catheter located in the right atrium. Fluid bolus temperature was detected by two serial in-line sensors of the two cardiac output computers (PATD: AS3, Datex-Ohmeda, Finland and TPTD: PiCCO Plus ${ }^{\mathrm{TM}}$, software version 6.0, Pulsion Medical Systems, Munich, Germany). The temperature changes in the pulmonary artery and in the abdominal aorta were simultaneously recorded with the two thermistor-tipped catheters and $\mathrm{CO}$ was calculated based on the Stewart-Hamilton equation by the corresponding $\mathrm{CO}$ computer. All temperature curves were visually controlled for regular shape.

To exclude a systematic error by a potentially increased dead space of the two serial in-line temperature sensors alternating measurements each with its own injectate sensor were performed additionally to the simultaneous recordings (both in triplicate). When mean bias of alternating measurements was equal or higher than mean bias of simultaneous measurements, all measurements were pooled and analyzed. The electrocardiogram was constantly screened for occurring arrhythmias, especially during the injection of the cold dextrose solution.

\subsection{Protocol}

After the instrumentation and stabilization period a first set of 3-5 simultaneous measurements was performed until 3 measurements were within $10 \%$. Subsequently a constant rate infusion of dobutamine $(10 \mathrm{mcg} / \mathrm{kg} / \mathrm{min})$ was started in order to increase CO. After stabilization (20 $\mathrm{min}$ ) a new set of 3-5 measurements was performed and the infusion was stopped thereafter. Twenty minutes later the next set of measurements was performed. The animals receivedalways in the same order-dobutamine, dopamine (each $10 \mathrm{mcg} / \mathrm{kg} / \mathrm{min})$, phenylephrine $(3 \mathrm{mcg} / \mathrm{kg} / \mathrm{min})$, medetomidine $(2 \mathrm{mcg} / \mathrm{kg} / \mathrm{h})$ and increased concentrations of isoflurane $(2 \times$ MAC) respectively in order to manipulate the $\mathrm{CO}$ stepwise over a broad range. The values of the pulse contour analysis were noted before a new set of bolus measurements was performed. The mean of the three nearest PATD measurements was calculated for further analysis. The pulse contour device was recalibrated with every new set of TPTD measurements. Data was indexed to body weight and is presented as cardiac index $(\mathrm{CI}=\mathrm{CO} / \mathrm{kg})$.

\subsection{Statistical analysis}

Agreement between the two techniques was quantified by the method described by Bland and Altman for multiple observations per individual [19]. Mean bias and limits of agreement (LOA) [mean bias \pm 1.96 standard deviation (SD) of the difference] were calculated. To objectify the agreement percentage bias $[100 \%$ (mean bias/mean CO of the two methods)] and percentage error [100\% (1.96 x SD of the bias)/mean $\mathrm{CO}$ of the two methods] were calculated [20, 21]. 

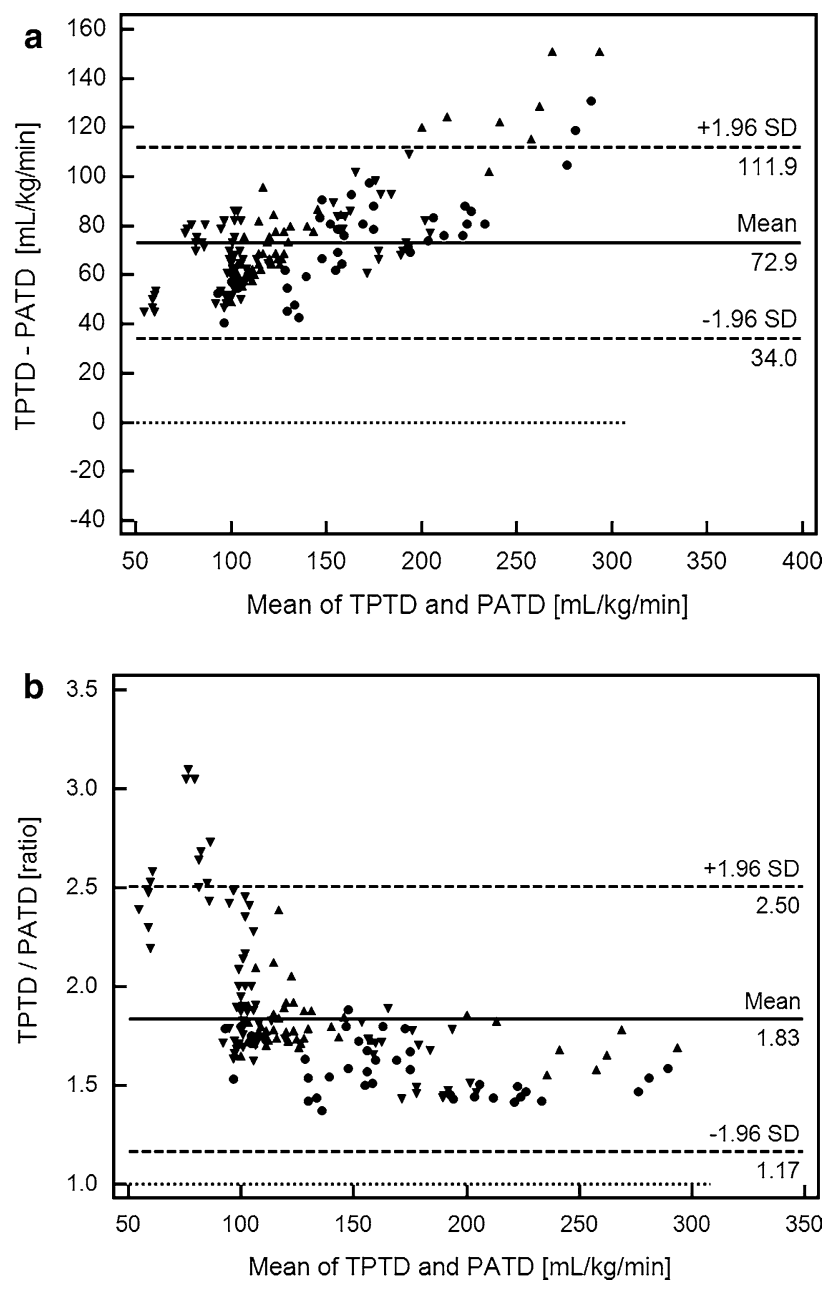

Fig. 1 a and b Bland-Altman analysis for multiple comparisons per individual with PATD and TPTD. a Absolute values, $\mathbf{b}$ ratio of TPTD/PATD. Solid line mean bias; broken lines limits of agreement (bias $\pm 1.96 \mathrm{SD}$ ); dotted line line of equality. Filled circle cat 1 , filled triangle cat 2, filled inverted triangle cat 3: each sign represents measurements from one individual cat

To assess the trending ability percentage changes of $\mathrm{CO}$ $(\triangle \mathrm{CO})$ were calculated after each set of measurements and compared using concordance rates and polar plots as recently described by Critchley et al. [22, 23]. The exclusion zone was set at changes of $\mathrm{CO}$ of $\leq 10 \%$.

Data management and graphs were performed using Excel for Macintosh (Office X, Microsoft, Seattle, USA). Statistical analysis was done with MedCalc 12.4 (MedCalc Software, Ostend, Belgium) and SigmaPlot 10.0 (Systat Software, San Jose, USA).

\section{Results}

A total of 160 (124 simultaneous and 36 alternating) paired measurements with PATD and TPTD were obtained. As

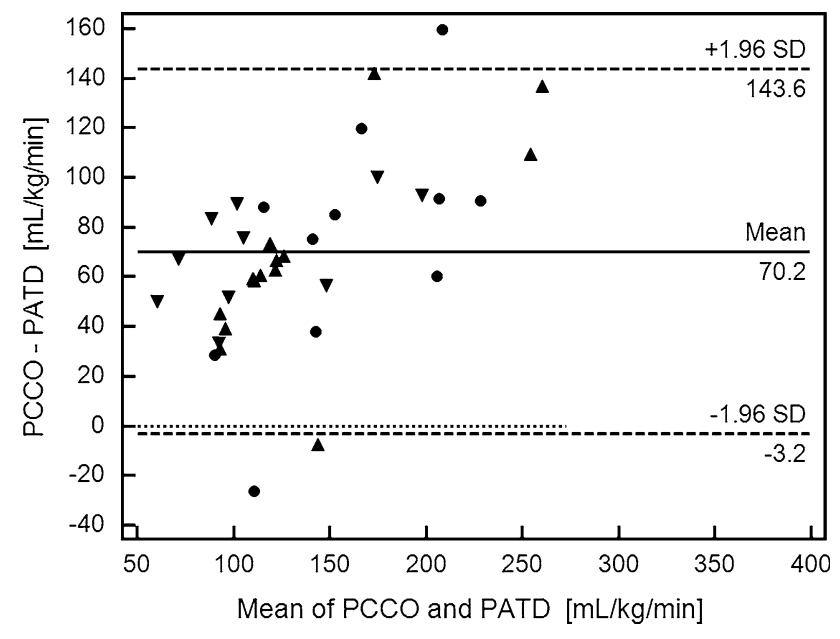

Fig. 2 Bland-Altman analysis for multiple comparisons per individual with the mean of the three nearest PATD measurements and PCCO. Solid line mean bias; broken lines limits of agreement (bias $\pm 1.96 \mathrm{SD}$ ); dotted line line of equality. Filled circle cat 1, filled triangle cat 2, filled inverted triangle cat 3: each sign represents measurements from one individual cat

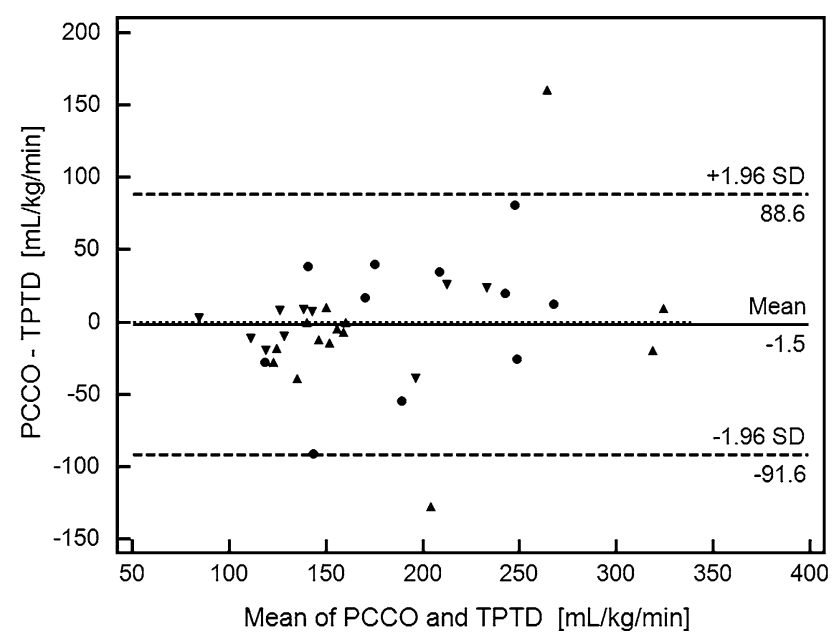

Fig. 3 Bland-Altman analysis for multiple comparisons per individual with the mean of the three nearest TPTD measurements and PCCO. Solid line mean bias; broken lines limits of agreement (bias $\pm 1.96 \mathrm{SD}$ ); dotted line line of equality. Cave: different scales in this graph. Filled circle cat 1 , filled triangle cat 2 , filled inverted triangle cat 3: each sign represents measurements from one individual cat

mean values and mean bias of alternating measurements were not different to simultaneous measurements a combined data analysis was performed. $\mathrm{CI}_{\mathrm{TPTD}}$ were constantly higher compared to $\mathrm{CI}_{\text {PATD }}$ with a mean bias of $73 \mathrm{~mL} / \mathrm{kg} /$ min (ratio 1.83) and LOA of $34-112 \mathrm{~mL} / \mathrm{kg} / \mathrm{min}$ (ratio 1.17-2.5) (Fig. 1a, b). Absolute bias was increasing with increasing CI (Fig. 1a), whereas relative bias was higher in low flows (Fig. 1b). 


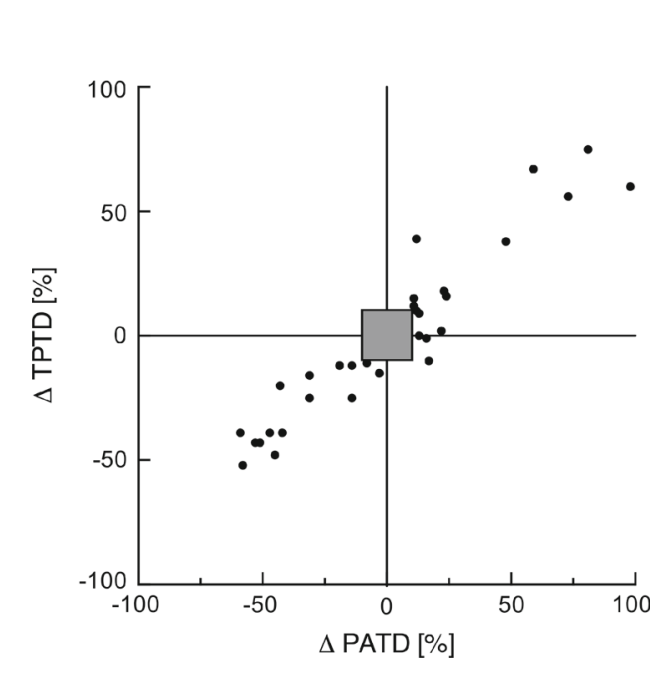

a

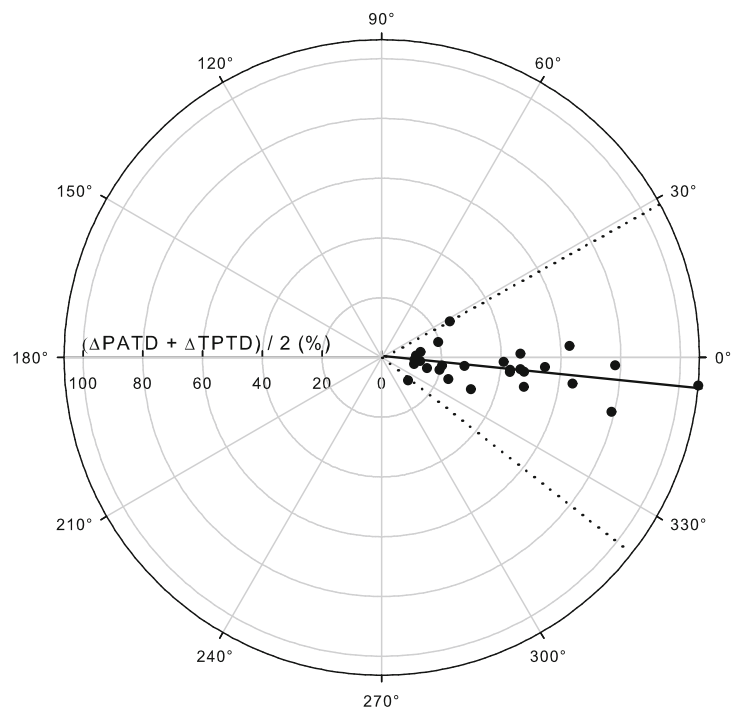

b
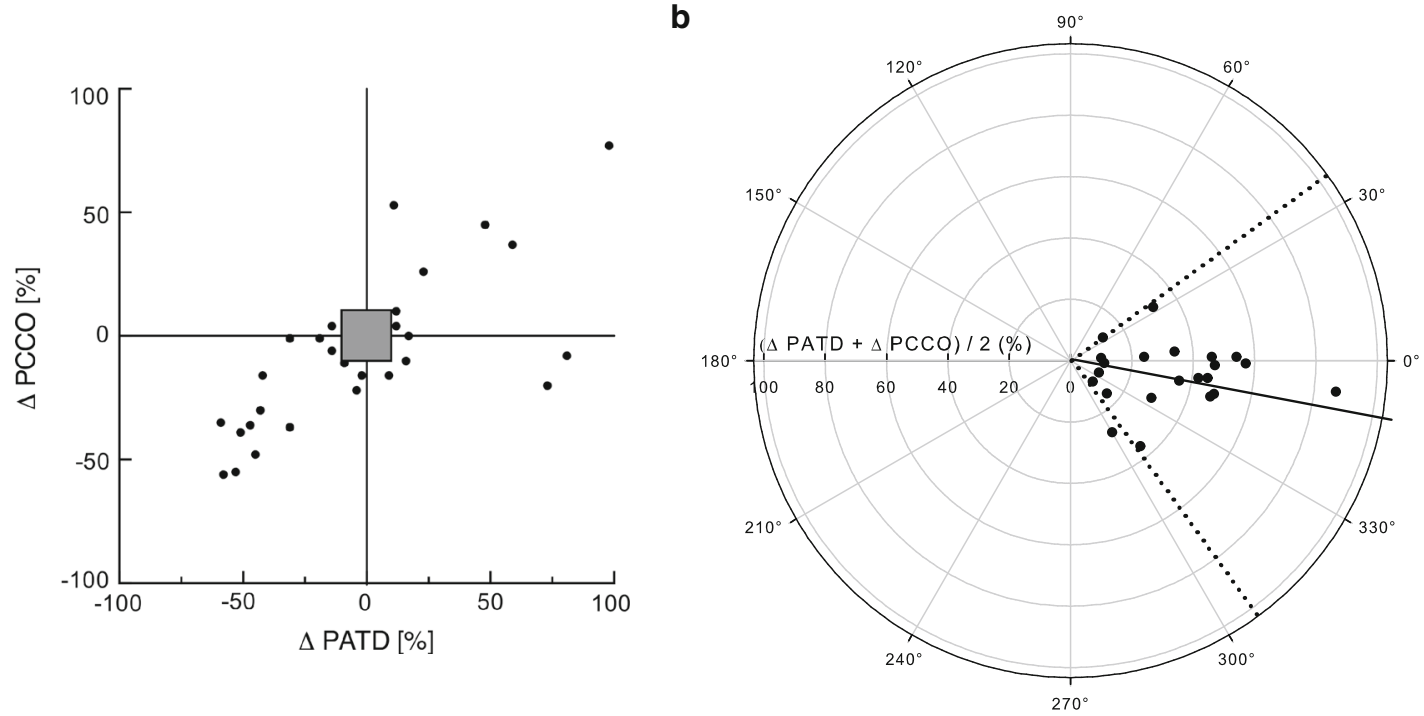

c
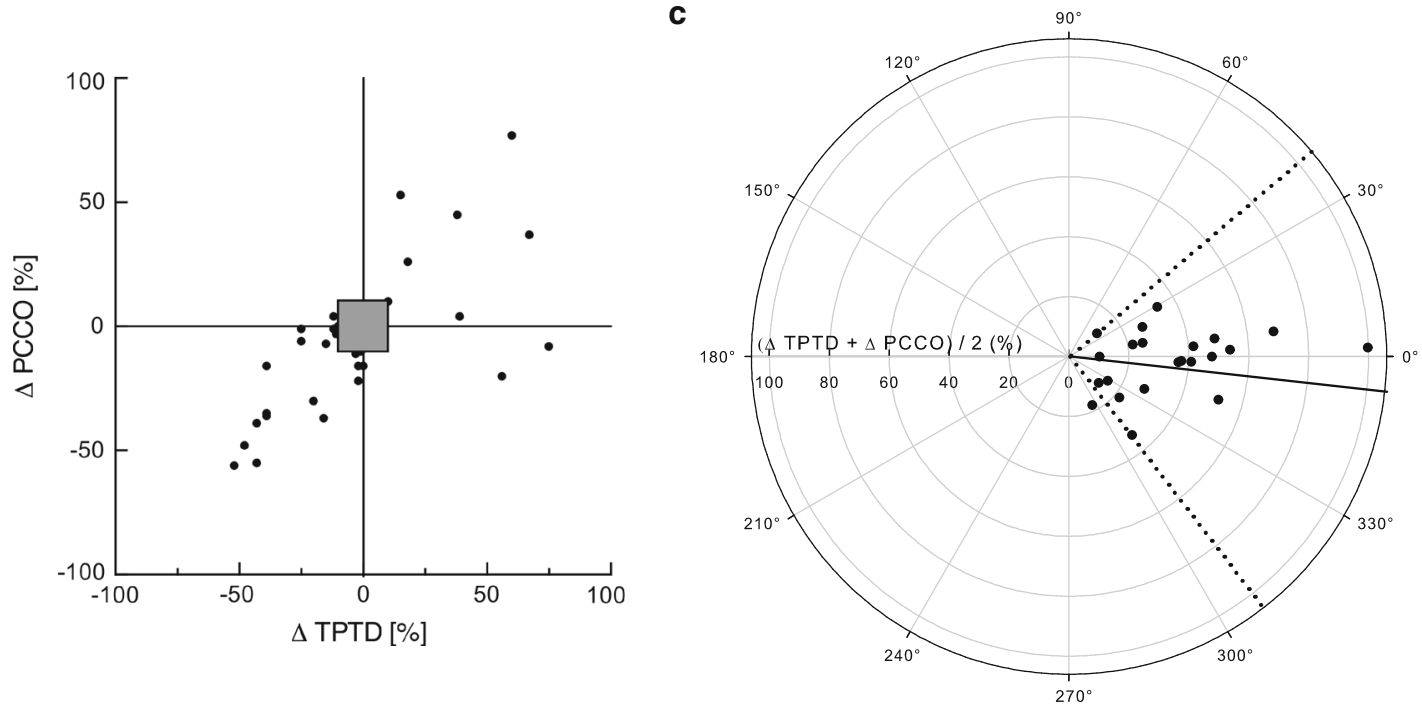
4Fig. 4 a-c Four quadrant and polar plots of mean percentage changes of cardiac output measurements (mean $\Delta \mathrm{CO}$ ) with PATD versus TPTD and PCCO. The exclusion zone was set at changes of $\leq 10 \%$. Concordance rates were $94 \%$ (acceptable) for TPTD (a), for PCCO $82 \%$ (poor) versus PATD (b) and $90 \%$ (acceptable) versus TPTD (c). Half circle polar plots are shown with data transformed to positive directional data only, distance from the center showing mean change in cardiac output. The mean polar angle for TPTD versus PATD was $-5^{\circ}$ with a SD of $\pm 12^{\circ}$ and radial limits of agreement (RLOA) of $\pm 33^{\circ}$ (acceptable trending) (a). For PCCO versus PATD it was $-10^{\circ}, \mathrm{SD} \pm 23^{\circ}$ with RLOA of $\pm 46^{\circ}$ (poor trending) (b) and for PCCO versus TPTD it was $-6^{\circ}, \mathrm{SD} \pm 26^{\circ}$ with RLOA of $\pm 46^{\circ}$ (poor trending) (c). Solid line mean polar angle; dotted lines radial limits of agreement

Median $\mathrm{CI}_{\text {PATD }}$ was $84 \mathrm{~mL} / \mathrm{kg} / \mathrm{min}$ (range 32-224 mL/ $\mathrm{kg} / \mathrm{min}$ ) and median $\mathrm{CI}_{\mathrm{TPTD}}$ was $153 \mathrm{~mL} / \mathrm{kg} / \mathrm{min}$ (77-369 $\mathrm{mL} / \mathrm{kg} / \mathrm{min})$. The calculated percentage bias of the two bolus method was $55.4 \%$ and the percentage error $29.5 \%$. $\mathrm{CI}_{\mathrm{PCCO}}$ compared to $\mathrm{CI}_{\mathrm{PATD}}$ revealed a mean bias of $70 \mathrm{~mL} / \mathrm{kg} / \mathrm{min}$ and LOA of -3 to $144 \mathrm{~mL} / \mathrm{kg} / \mathrm{min}$ (Fig. 2). Comparing $\mathrm{CI}_{\mathrm{PCCO}}$ to its calibration method $\mathrm{CI}_{\text {TPTD }}$ gave a mean bias of $-2 \mathrm{~mL} / \mathrm{kg} / \mathrm{min}$ and LOA of -92 to $89 \mathrm{~mL} / \mathrm{kg} / \mathrm{min}$ (Fig. 3).

Concordance rates between $\mathrm{CI}_{\mathrm{PATD}}$ and $\mathrm{CI}_{\mathrm{TPTD}}$ were 94 , $83 \%$ between $\mathrm{CI}_{\mathrm{PATD}}$ and $\mathrm{CI}_{\mathrm{PCCO}}$ and $90 \%$ between $\mathrm{CI}_{\text {PCCO }}$ and $\mathrm{CI}_{\text {TPTD }}$ (Fig. $4 \mathrm{a}-\mathrm{c}$ ).

The mean polar angle for $\mathrm{CI}_{\mathrm{PATD}}$ versus $\mathrm{CI}_{\mathrm{TPTD}}$ was $-5^{\circ}$ with a SD of $\pm 12^{\circ}$ and radial LOA of $\pm 33^{\circ}$ (Fig. 4a) For $\mathrm{CI}_{\mathrm{PCCO}}$ versus $\mathrm{CI}_{\mathrm{PATD}}$ and versus $\mathrm{CI}_{\mathrm{TPTD}}$ it was $-10^{\circ} \pm 23^{\circ} \mathrm{SD}$ with radial LOA of $\pm 46^{\circ}$ and $-6^{\circ} \pm 26^{\circ}$ SD with radial LOA of $\pm 46^{\circ}$ respectively (Fig. $4 \mathrm{~b}, \mathrm{c}$ ).

\section{Discussion}

This study evaluated CO assessed by TPTD and PCCO against PATD over a wide range of flows in small animals. It evaluated the trending abilities with a new quantitative approach [22, 23]. The concordance rate was $94 \%$ and the mean polar angle $-5^{\circ}$ with radial LOA of $\pm 33^{\circ}$ for the intermittent bolus technique TPTD, which is considered an acceptable result. Opposed to this the continuous PCCO algorithm showed poor trending (Fig. 4b, c) as described before $[17,18]$. We found a much higher mean bias of the intermittent TPTD versus the reference method as compared to published data in pediatric patients or other animal studies [9-13].

In a similar study in cats [12] the mean bias was only $-3.7 \mathrm{~mL} / \mathrm{kg} / \mathrm{min}$ with LOA of -36 to $29 \mathrm{~mL} / \mathrm{kg} / \mathrm{min}$. In that study PATD results were measured with $1.5 \mathrm{~mL}$ room temperature injectate. In our study we injected $3 \mathrm{~mL}$ icecold injectate. This can result in transient bradycardia [24], which we observed but did not quantitatively assess.
The large amount of cold injectate was used as it was described in the manual of the PAC. As the temperature difference is measured earlier with PATD, this technique is more sensitive to a very short lasting drop in heart rate that can potentially result in lower PATD values than the more peripheral measurements with TPTD. Furthermore $1 \mathrm{~cm}$ longer catheters were used in that study than in our study. This might have resulted in a proximal versus a distal placement of the catheter tip in the range of the descending aorta-iliacal artery. In post mortem examination of similar-sized cats the thermistor lay at least $1 \mathrm{~cm}$ distal to the bifurcation. The influence of the site of detection was studied in rabbits $(\cong 3 \mathrm{~kg})$ and an irreversible loss of indicator occurred when the thermistor was in the femoral artery [25].

In an experimental model with lambs of a median weight of $6 \mathrm{~kg}$ a much smaller absolute $(0.19$ vs. $0.36 \mathrm{~L} /$ min) and percentage mean bias ( 12 vs. $55 \%$ in our study respectively) were measured [13]. We were measuring lower $\mathrm{CO}$ values with a minimal $\mathrm{CO}$ of $0.18 \mathrm{~L} / \mathrm{min}$ compared to the reported study where the lowest $\mathrm{CO}$ was $0.5 \mathrm{~L} /$ min. In our study the percentage bias was increased during low flow states. The TPTD has been shown to be susceptible to errors in low flow conditions [25, 26]. In rats a loss of cold indicator over the thin vessel walls led to an overestimation of CO of around $50 \%$ with TPTD compared to direct Fick and electromagnetic flowmetry. When $\mathrm{CO}$ was decreased, the longer transit time of the cold indicator allowed for an additional heat exchange and increased loss of indicator and overestimation of $\mathrm{CO}$ up to several hundred percent occurred [26].

The reference PATD technique has been validated in cats against an in vitro model [27], echocardiography [28], direct Fick [28] and a microspheres technique [29] and has shown to provide consistent and reliable results.

In a comparison of two cardiac output measurement techniques with an estimated measurement error of the single method of up to $20 \%$ a percentage error of $30 \%$ has been proposed as acceptable threshold value [20, 21]. In the present study percentage error was $<30 \%$ and therefore TPTD might be recommended as a replacement of PATD for cardiac output measurement in this setting. However a percentage bias of $55 \%$ indicates that the techniques cannot be used interchangeably even if the trending abilities are good and documented all changes.

Intermittent assessment of $\mathrm{CO}$ may miss rapid changes of the hemodynamic situation and therefore a time-sensitive continuous monitoring must be considered a prerequisite to accomplish this task. However, for reliable performance, pulse contour techniques need to be recalibrated after major changes in vascular tone or volume status [30]. This may preclude robust trend analysis and in 
fact, this might explain the poor trending ability of PCCO in the present study.

The small size of the cats, low flows and a relative too short catheter probably led to an overestimation of the real CO with TPTD and the cold injectate by inducing transient bradycardia to an underestimation of the real $\mathrm{CO}$ with PATD. All these factors could be relevant in the pediatric patient population, and therefore correct positioning of the arterial catheter with the thermistor lying above the bifurcation of the descending aorta and room warm injectate could be a key for reliable measurements. As a main limitation only three cats were measured in the current study. The pulse contour system with its catheters and lines was not specifically tested for damping but flushed continuously. Over- or underdamping is a possible source of error as the quality of the signal is essential for a reliable pulse contour analysis. However testing for excessive damping is often not done in clinical patients on a routine basis even if this would be desirable. The measurements were performed in animals under anesthesia and CO changes were achieved by pharmacological measures.

The applicability of the current results to critically ill children needs to be tested with further studies comparing TPTD and PCCO trending ability to standard techniques.

\section{Conclusions}

In the present animal study TPTD revealed consistently higher $\mathrm{CO}$ values than PATD but it tracked $\mathrm{CO}$ changes even at very low flows with an acceptable concordance rate of $94 \%$. Absolute values of TPTD and PATD cannot be used interchangeably. Trending of the continuous pulse contour technique was poor as described before in cardiovascular unstable patients.

Acknowledgments This study was funded solely by departmental sources of the Vetsuisse Faculty of Zurich.

Conflict of interest In the past Christoph K. Hofer has received research grants and lecture fees from Pulsion Medical Systems.

\section{References}

1. Ceneviva G, Paschall JA, Maffei F, Carcillo JA. Hemodynamic support in fluid-refractory pediatric septic shock. Pediatrics. 1998;102:e19.

2. Carcillo JA, Fields AI. Clinical practice parameters for hemodynamic support of pediatric and neonatal patients in septic shock. Crit Care Med. 2002;30:1365-78.

3. Skowno JJ, Broadhead M. Cardiac output measurement in pediatric anesthesia. Pediatr Anesth. 2008;18:1019-28.

4. Tibby SM, Murdoch IA. Measurement of cardiac output and tissue perfusion. Curr Opin Pediatr. 2002;14:303-9.
5. Brierley J, Carcillo JA, Choong K, et al. Clinical practice parameters for hemodynamic support of pediatric and neonatal septic shock: 2007 update from the American College of Critical Care Medicine. Crit Care Med. 2009;37:666-88.

6. Tibby SM, Hatherill M, Marsh MJ, Murdoch IA. Clinicians' abilities to estimate cardiac index in ventilated children and infants. Arch Dis Child. 1997;77:516-8.

7. Egan JR, Festa M, Cole AD, Nunn GR, Gillis J, Winlaw DS. Clinical assessment of cardiac performance in infants and children following cardiac surgery. Intensive Care Med. 2005;31:568-73.

8. Damen J, Wever JE. The use of balloon-tipped pulmonary artery catheters in children undergoing cardiac surgery. Intensive Care Med. 1987;13:266-72.

9. Tibby SM, Hatherill M, Marsh MJ, Morrison G, Anderson D, Murdoch IA. Clinical validation of cardiac output measurements using femoral artery thermodilution with direct Fick in ventilated children and infants. Intensive Care Med. 1997;23:987-91.

10. Ruperez M, Lopez-Herce J, Garcia C, Sanchez C, Garcia E, Vigil D. Comparison between cardiac output measured by the pulmonary arterial thermodilution technique and that measured by the femoral arterial thermodilution technique in a pediatric animal model. Pediatr Cardiol. 2004;25:119-23.

11. McLuckie A, Murdoch IA, Marsh MJ, Anderson D. A comparison of pulmonary and femoral artery thermodilution cardiac indices in paediatric intensive care patients. Acta Paediatr. 1996;85:336-8.

12. Beaulieu KE, Kerr CL, McDonell WN. Evaluation of transpulmonary thermodilution as a method to measure cardiac output in anesthetized cats. Can J Vet Res. 2009;73:1-6.

13. Lemson J, de Boode WP, Hopman JC, Singh SK, van der Hoeven JG. Validation of transpulmonary thermodilution cardiac output measurement in a pediatric animal model. Pediatr Crit Care Med. 2008;9:313-9 (see comment).

14. Tibby S. Transpulmonary thermodilution: finally, a gold standard for pediatric cardiac output measurement. Pediatr Crit Care Med. 2008;9:341-2.

15. Hanna BD. Where do we go from here? Cardiac output determination in pediatrics. Crit Care Med. 2008;36:1377-8.

16. Proulx F, Lemson J, Choker G, Tibby SM. Hemodynamic monitoring by transpulmonary thermodilution and pulse contour analysis in critically ill children. Pediatr Crit Care Med. 2011;12:459-66.

17. Fakler U, Pauli C, Balling G, Lorenz HP, Eicken A, Hennig M, Hess J. Cardiac index monitoring by pulse contour analysis and thermodilution after pediatric cardiac surgery. J Thorac Cardiovasc Surg. 2007;133:224-8.

18. Mahajan A, Shabanie A, Turner J, Sopher MJ, Marijic J. Pulse contour analysis for cardiac output monitoring in cardiac surgery for congenital heart disease. Anesth Analg. 2003;97:1283-8.

19. Bland JM, Altman DG. Agreement between methods of measurement with multiple observations per individual. J Biopharm Stat. 2007;17:571-82.

20. Critchley L, Critchley J. A meta-analysis of studies using bias and precision statistics to compare cardiac output measurement techniques. J Clin Monit Comput. 1999;15:85-91.

21. Tibballs J, Hochmann M, Osborne A, Carter B. Accuracy of the BoMED NCCOM3 bioimpedance cardiac output monitor during induced hypotension: an experimental study in dogs. Anaesth Intensive Care. 1992;20:326-31.

22. Critchley LA, Lee A, Ho AM-H. A critical review of the ability of continuous cardiac output monitors to measure trends in cardiac output. Anesth Analg. 2010;111:1180-92.

23. Critchley LA, Yang XX, Lee A. Assessment of trending ability of cardiac output monitors by polar plot methodology. J Cardiothor Vasc Anesth. 2011;25:536-46. 
24. Nishikawa T, Dohi S. Errors in the measurement of cardiac output by thermodilution. Can J Anaesth. 1993;40:142-53.

25. Warren DJ, Ledingham JG. Cardiac output in the conscious rabbit: an analysis of the thermodilution technique. J Appl Physiol. 1974;36:246-51.

26. Kissling G, Ross C, Brandle M. Validity of thermal dilution technique for measurement of cardiac output in rats. Am J Physiol Heart Circ Physiol. 1993;265:1007-13.

27. Dyson DH, McDonell WN, Horne JA. Accuracy of thermodilution measurement of cardiac-output in low flows applicable to feline and small canine patients. Can J Comp Med. 1984;48:425-7.
28. Dyson DH, Allen DG, McDonell WN. Comparison of three methods for cardiac output determination in cats. Am J Vet Res. 1985;46:2546-52.

29. Arvidsson S, Bergqvist D, Haglund U, Lindblad B. Cardiac output measurements with thermodilution and radioactive microspheres. A comparative study in cats. Scand J Clin Lab Invest. 1983;43:617-20.

30. Piehl MD, Manning JE, McCurdy SL, Rhue TS, Kocis KC, Cairns CB, Cairns BA. Pulse contour cardiac output analysis in a piglet model of severe hemorrhagic shock. Crit Care Med. 2008;36:1189-95 (see comment). 